Review Article

\title{
Assessing the Benefits and Challenges of Distributed Generation in Nigeria Power Distribution Network
}

\author{
Stephen Adole Benson, Evans Chinemezu Ashigwuike, Jacob Kehinde Ogunjuyigbe \\ Department of Electrical and Electronic Engineering, University of Abuja, Abuja, Nigeria \\ Email address: \\ iamsteveben@gmail.com (S. A. Benson)
}

\section{To cite this article:}

Stephen Adole Benson, Evans Chinemezu Ashigwuike, Jacob Kehinde Ogunjuyigbe. Assessing the Benefits and Challenges of Distributed Generation in Nigeria Power Distribution Network. International Journal on Data Science and Technology. Vol. 5, No. 1, 2019, pp. 8-13. doi: $10.11648 /$ j.ijdst.20190501.12

Received: March 7, 2019; Accepted: April 12, 2019; Published: May 20, 2019

\begin{abstract}
The growing concern for the need to reduce the gap between power generated and power consumed in Nigeria is on the increase. Many measures and policy have been geared by Nigeria Electricity Regulatory Commission and Ministry of Power to revamp the generation aspect of the country power sector but the impact is yet to be felt as the amount of power still generated is far below par compared to other countries. Nigeria average power generation stands at an average of $5800 \mathrm{MW}$. With the call to see the need of exploring Distributed generation in augmenting the power generated, this paper reviews the benefits and challenges of integrating Distributed generation into the present power system distribution network may pose.
\end{abstract}

Keywords: Distributed Generation, Distribution Network, Benefit, Challenges

\section{Introduction}

Electricity power has remained an essential prerequisite for the progress of any country's economy whether developed, emerging or developing. Increasing human activities due to technological advancement coupled with population growth, has made the demand for power more than doubling by the decades, thereby broadening the gap between power generated and the demand by the consumer.

Conservatively, the existing power system in Nigeria is one in which power is generated conventionally at remote stations and transmitted at high voltage through the transmission station to the distribution network, and subsequent delivery to the end consumers at a lower voltage level. Thus, the capability of humans to develop sources of energy necessary to realize useful task has played a critical role in the recurrent improvement of the standard of living generally.

Hence, with the increase in power consumption, achieving the power demand of consumers at all location within the power network economically and dependably as possible has become the ultimate aim of the power system. The traditional practice of the electricity power generation system utilizes the conventional energy sources among which in Nigeria commonly used are the hydro and thermal with gradual advances in solar [1]. To this end, this paper review the likely benefits there is to achieve should the outcry for the introduction of Distributed generation come to effect and also narrate certain challenges inherent with the integration of the system.

\subsection{Conventional Concept of Power System in Nigeria}

The power system in Nigeria like every other country is a system that is made up of generation, transmission and distribution system. It applies basically hydro and gas as forms of energy sources, and converts it into electrical energy; other salient sources of energy are solar, and diesel but used mainly in captive power generation. The power system consists of devices coupled or linked to the system like the synchronous generator, motor, transformer, circuit breaker, conductor, etc. [2]. The major component of the power system that constitutes its structure is the power plant, transformer, transmission line, substations, distribution line, and distribution transformer. Power generation takes place at the generating station which is located at a remote location with subsequent stepping-up or stepping-down via the transformer for transmission. The transmission line transmits the power to the various 
sub-stations cut across the country. Through sub-station, the power is transmitted to the distribution transformer which step-down the power to the appropriate value which is fit for consumers' usage.

\subsection{Distribution System}

The distribution system is the finishing phase in the conveyance of electric power; as it transmits electricity from the transmission system to different consumers. Also, it links the transmission system and lowers the transmitted to a voltage with the aid of a transformer; the distribution lines in Nigeria basically carry the lower voltage to the distribution transformer situated near the consumers. With several arrangement of the distribution network, in Nigeria, the radial distribution system, has main feeder and lateral distributor which originate from the substation and passes through different consumer loads [3]. The radial systems of distribution are used because of their ease and the layout of residential and industrial zones. Hence, power losses in a distribution network are a function of how low or high the voltage is, putting into consideration the current [4].

Electrical networks recently in advance countries are in the epoch of key transition from steady passive distribution networks with uni-directional electricity delivery to active distribution networks with bi-directional electricity delivery.
Radial distribution networks without any distributed generation units are taken as passive meanwhile the electrical power is supplied by the nationwide grid system to the customers within the distribution networks. They become active when distributed generation unit(s) is included to the distribution system leading to bi-directional power flows in the networks (as in some case the smart grid) [5].

In an active distribution network, the amount of electrical power lost in transmitting electricity is a quite reduced compared to the passive distribution network, because the electricity is generated very close to the load center.

\section{Concept and Benefits of Distributed Generation}

Over the years, the increasing cases of installed peripheral power generating facilities had encouraged the publication of several articles especially with the Nigeria ministry of power getting aware and recognizing the potential therein with distributed generation. Data obtained from the Transmission Company of Nigeria and put forward by Premium Times shows that daily power generation for the month of January never surpasses the $5 \mathrm{MW}$ threshold as seen in the figure 1

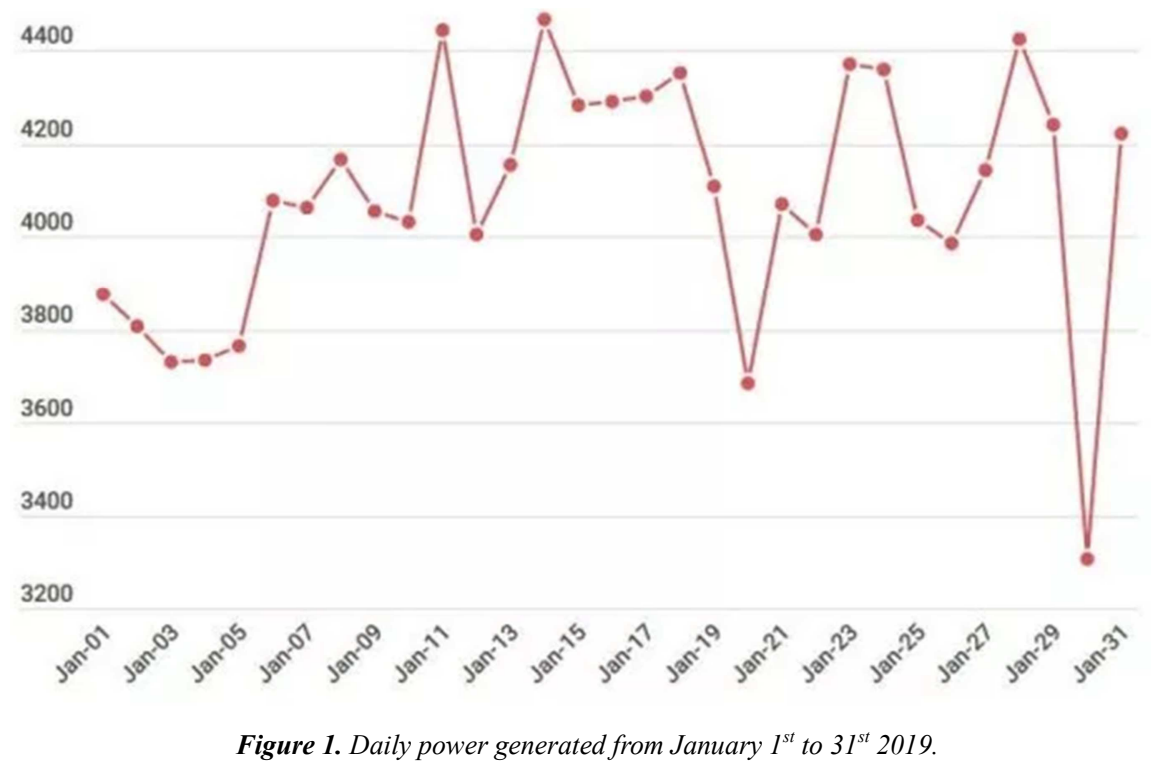

To argument the demand for power generated, the need for distributed generation could be a panacea for improvement and sustenance in the power section in Nigeria.

Distributed generation by definition is an electric power unit or source coupled directly to the distribution network or the consumers' side of the meter [6]. CIGRE describe it as a concept of generation, which is characterized as follows; (CIGRE, 1999): it is not centrally strategic or planned; it is not centrally dispatched at present; it is usually connected to the distribution networks; it is smaller than 50-100MW [7]

The benefits of distributed generation can be broadly categorized into three. These are consumers' benefits, suppliers' benefits, and national benefits.

\subsection{Customer Benefits}

Accurately located, installed and operated distributed generation can improve and enhance the reliability of power supply, increasingly critical to business and industry in general, and essential to place where interruption of service is undesirable economically or where health and safety is impacted; [8] The numerous distributed generation technologies offer the chance of choosing the right energy solution at the right location. The technology can deliver a stand-alone power choice for areas where transmission and 
distribution infrastructure does not exist or is too costly to build; distributed generation might offer efficiency gains for on-site applications by eluding line losses and using both electricity and the heat produced in power generation for processes or heating and air conditioning.

Distributed generation flexibility or suppleness of operation because of small modular unit permits savings on electricity rates by self-generating for the duration of high-cost peak power periods and adopting relatively low-cost interruptible power rates. Benefits for environmental quality could come from distributed generation role in promoting and supporting renewable energy sources, less-polluting forms of fossil energy, and high efficiency technologies. Distributed generation allows power to be supplied in environmentally sensitive and developed areas by having typically high efficiency and near-zero pollutant emissions; Affords consumers a choice in adequately meeting their particular energy needs; and provides sitting suppleness or flexibility by the benefit of the small size, superior environmental performance, and fuel flexibility.

\subsection{Supplier Benefits}

Distributed generation limits capital exposure and menace or risk because of the size, siting flexibility, and rapid installation time afforded by the small, modularly constructed, environmentally friendly, and fuel flexible systems and Avoidable capital expenditure can be prohibited by thoroughly matching capacity increases to growth in demand; distributed generation avoids major or main investments in transmission and distribution system upgrades by siting new generation near the consumer as it offers a relatively low-cost entry point into a new and competitive market; and opens markets in remote areas without transmission and distribution systems, and areas without power because of environmental concerns, hence providing a platform for the micro grid to thrive.

\subsection{National Benefits}

Distributed generation technologies that are depended on renewable energy sources might yield environmental benefits by way of reduced emissions of contaminant and or pollutants and greenhouse gases if perhaps those technologies displace power supplied by the utility company, much of which is generated from gas and coal. Technologies that relied on conventional fuels would yield environmental benefits if they resulted in a shift to energy source that is less-polluting an example of which is, solar rather than gas or coal.

Technologies with high efficiency possibly will produce benefits by decreasing the quantity of energy essential to yield a unit of electricity. [9] Distributed generation reacts to increasing energy demands and pollutant emission trepidations or concerns although providing the low-cost, dependable and reliable energy needed for maintaining competitiveness in the world market; and creates new industry valued billions of naira in sales and provide a good number of jobs opportunities and enhances productivity via improved reliability and quality of electric power delivered, valued at billions of naira annually. A typical example is the Green Village Electricity (GVE) operating micro grid in some part of the country with most located in Jos, Plateau State Nigeria.

\section{Challenges and Issues with Distributed Generation}

The issues confronting distributed generation in a distribution network ranges from technical, interconnection, protection, commercial and planning issues. These issues or challenges as the case may be are discussed briefly below. These challenges though inherent, they are a microcosm of what is mostly in existence in the distribution.

\subsection{Technical Issues}

The key technical issues for a distributed generation connection relate to quality and reliability of supply, metering, protection and operating protocols for islanding and reactive power management, connection and disconnection. Vital quality of supply issue includes DC injection, harmonics (i.e., steady-state distortion of the fundamental frequency $(50 \mathrm{~Hz})$ with potentials of causing overheating of transformers and rotating equipment, failed capacitor banks, wasted capacity inefficient distribution of power), voltage regulation (i.e. the degree of steadiness of the root mean square voltage at the load. It is regularly specified in relation to additional parameters, such as input voltage changes, load changes, or temperature changes) and flickers (an occurrence caused by small magnitude change (few percents of nominal) but the rapid fluctuation in system voltage that could result in observable changes in light output).

\subsection{Protection Issues}

Power system protection is a technical issue that is vital. The aim of power system protection is to detect a fault situation or condition (probably as a result of a lightning strike or equipment failure) and promptly isolate the faulty sector of the system to enable restoration and continuation of supply to the rest of the system. Protection issues eminent, both for distributed generation equipment and network equipment. Distributed generation protection issues are influenced by the type of generator and the features of the network. Connecting distributed generation to a distribution network introduces a source of energy at a point where there may be no energy source before which may upsurge the fault level in the network and may complicate fault detection and isolation. [10-11]

\subsection{Commercial and Planning Issues}

Some reservations surround the costs and benefits of distributed generation. In some conditions, distributed generation might be able to defer network augmentation costs, minimize network losses and improve or enhances power system quality and security of supply. In other conditions, distributed generation may impose other power system 
operating costs and necessitate investment in network assets. On the other hand, network service providers and system operators may feel that distributed generation proponents exaggerate the benefits of distributed generation; while on the one hand, distributed generation proponents may feel that network service providers and system operators exaggerate the costs. This variance in opinions may be unavoidable given the inventive nature of distributed generation and its perspective to radically change the electricity industry. Nonetheless, the shared nature of the electricity industry operation and investment also adds by obscuring accountabilities and thus obscuring both the nature of suitable commercial obligations and assessments of whether those obligations have been met.

Internationally, solutions are being followed through uniform business practices and regulatory procedures; even though this process is disadvantaged by the elementary nature of retail electricity markets in which both consumers and distributed generation participate. Preceding to the introduction of distributed generation, distribution network planners only had to consider the effect or influence of supply from the main grid generators. Distributed generation presents energy sources in distribution networks where they had not existed earlier, with a wide diversity of technology types and features. As the network provides the main channel for the distribution of electricity, the planner's main task is to be able to appraisal and forecast the location and size of a distributed generation connected to the network and to guarantee that the primary aims as set out above are achieved. Distributed generation can bring both positive and negative values from the viewpoint of distribution planning:

1. Positives can include the perspective to defer expenditure on network augmentation, reduce network losses and improve outcomes for the environment, voltage control and or availability and quality of supply

2. Negatives can include fears about safety and protection, amplified capital expenditure, deleterious effects on security and reliability of availability of supply, and worse outcomes for the local environment, voltage control and quality of supply. DG installations must be evaluated on a discrete basis, with the exception of very small less than $10 \mathrm{~kW}$ units, since the variation in DG sizes and technology types, and since the impact on the network can be location specific. This results in long application processing times and may acquire substantial costs. With better knowledge and understanding of the issues by all parties, the valuation of impacts will improve. "For small installations, there is a need for better standardization of conditions of connection.

For larger installations, there are significant issues to be addressed which tend to result in long application processing times and unexpected costs for the proponent" [12] [8].

\subsection{Interconnection Issues}

Considerable dialogue and discussion centering on distributed generation interconnection have focused on technical issues. Nevertheless, there are two rudiments of interconnection that are worth consideration-process and contractual issues. The essential question in the technical area is whether standards can be established that will permit for a cost-effective and operative interconnection solution that will not put in danger the security and dependability of the power system. Additionally, new technical requirements need to be developed to take care of the emerging needs of distributed generation for dispatch, metering, communication and control standards.

Another important interconnection issue is to establish a process and procedure that is clear and transparent to the consumer and efficient without excessively burdening and or encumbering distributed generation or distribution companies (or utility company). Hence, creating efficiency and reform existing and obtainable processes while sustaining safety and reliability, especially for the smaller size generators, will be a formidable task. The focal issues on interconnection contracts are the complexity and the suitability of standard contract requirements for distributed generation. An interconnection contract concerning a distributed generation owner (the case, where private players in Nigeria electricity supply industry get involves, example, micro grid developers) and a utility (Discos) is analogous to a contract concerning a central power facility (Nigeria Electricity Regulatory Commission) and a utility (Discos) in many respects although both are being regulated by Nigeria Electricity Regulatory Commission. Several of these contracts are often extensive and complex. Whereas developers admit that such contracts are appropriate for a $200 \mathrm{MW}$ facility, there are many requirements included in the standard contracts that are not suitable for a $200 \mathrm{~kW}$ facility. [13]

The distributed generation operation is typically referred to as a synchronized or parallel operation. In this configuration, the distributed generation is connected to the network at the same time that it is producing power and in the situation where the load is met and excess energy needs to be transmitted.

The parallel distributed generation operation is the most complex compared with a stand-alone distributed generation application. The complexity of the distributed generation operation mostly depends on the level of interaction with the existing network. The connection cases can be illustrated as thus:

1. The case where the load is met with distributed generation without any network connection. That is isolated and no grid source (stand-alone).

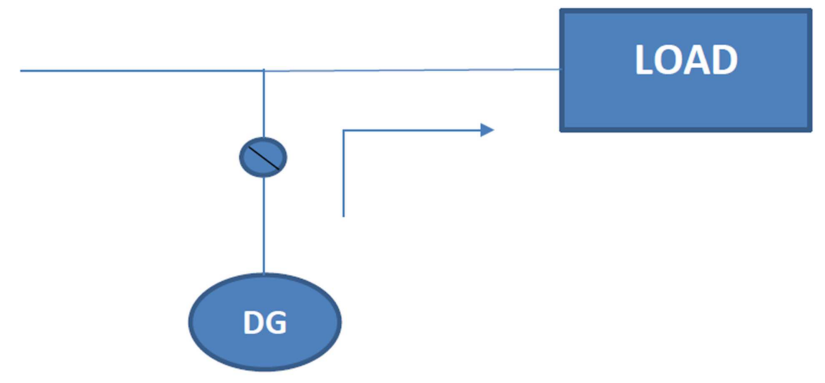

Figure 2. Isolated, standalone sources. 
2. The case, where there are 2 loads and the DG, delivers power to load, and the network covers both loads when needed. In this case, DG does not work in parallel except for a few seconds.

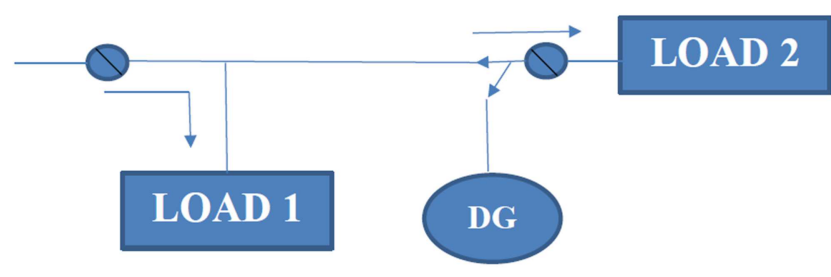

Figure 3. Isolated systems with automatic transfer.

The case where the DG operates in parallel to the grid by transmitting power to one or more loads without sending any excess energy to the grid.

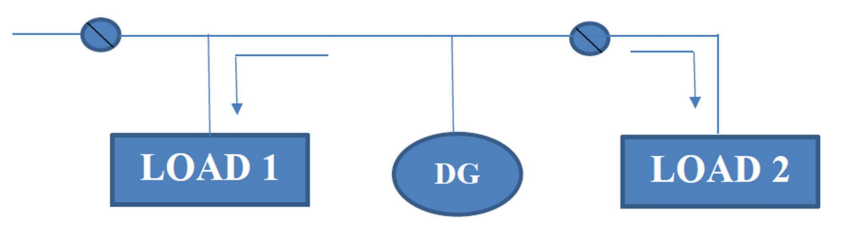

Figure 4. DG Connected to a Network with no Power Export..

3. The case where DG operates in parallel to the grid and there exists the option to supply any excess power to the grid. That is, DG grid interconnected with power export.

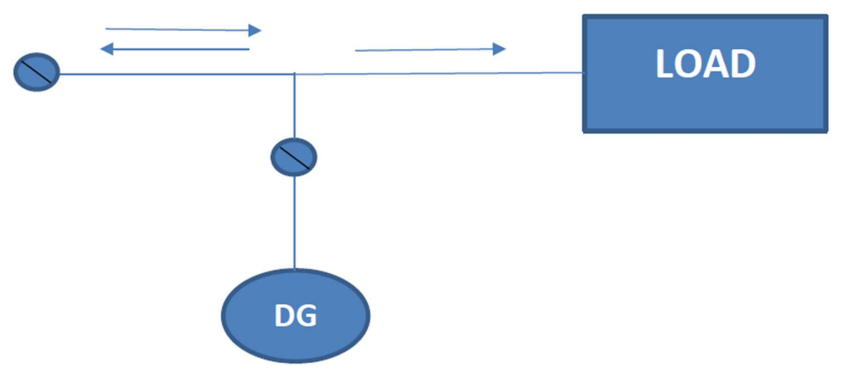

Figure 5. DG Grid interconnected with power Export..

4. Cases where the system supplies the base load, standby power, and peak load with the DG operating in parallel. That's grid interconnected with power export- utility side.

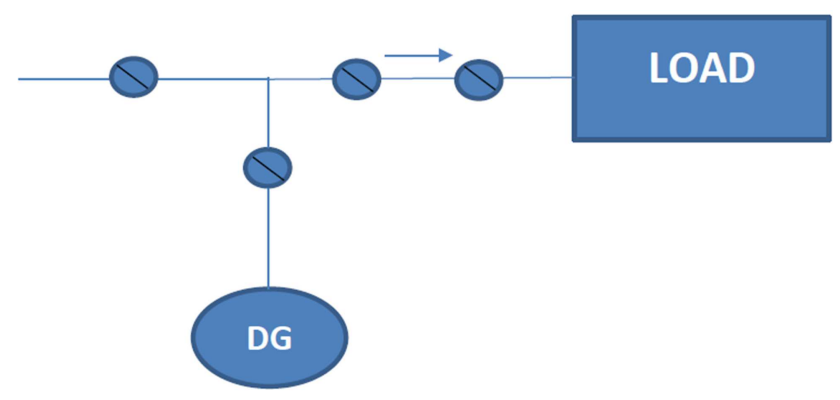

Figure 6. Grid interconnected with power export- utility side.

\section{Conclusion}

Distributed generation is anticipated to play a vital role in electrical power generation in the coming years, particularly at the consumer end since the goal of any power system is to ensure continuity in supply to the consumers; though this has been challenged by the widening gap as a result in increased population, technology and lifestyle. To meet the gap in demand, it is imperative to find a means to argument the power supply. Distributed generation as a means of generation of electrical power at smaller quantity and injecting into the distribution network will suffice in curtailing the challenges has been faced by the power sector in meeting consumers' demands.

With the availability of renewable energy such as solar energy especially in the northern region of the country Nigeria, there should be an increasing quest on the side of the regulators of the power sector to motivate investors and energy developers not just for the purpose of micro grid alone but also an interface where both can synergize with the DISCOs towards exploring this energy in line with the desire to expand and boost the power sector by means of incentives and increase consumers' confidence on the power sector. Furthermore, having seen the likely benefits and challenges of distributed generation, modalities should be enhanced for easy integration of the distributed generation into the distribution network with minimal harmonies and coordination of distribution system protection.

\section{References}

[1] Satish K., Sai B. B. R., Barjeev T., Vishal K., "Optimal Placement of Distributed Generation in Distribution Network," International Journal of Engineering, Science and Technology, Vol. 3, No. 3, 2011, pp. 47-55.

[2] Power System, http://circuitglobe.com/power-system.html Accessed 15/05/2018 12: 59.

[3] Short T. A, Electric Power Distribution Handbook, Boca Raton, Florida, USA, CRC press, 2004, pp.1-33, Available https: //goodboygunawan.files.wordpress.com/2010/03/electric-pow erdistribution- handbook.pdf.

[4] Mohammad M., Nasab M. A, "PSO Based Multi Objective Approach for Optimal Sizing and Placement of Distributed Generation," Research Journal of Applied Science, Engineering and Technology, Vol. 2, No. 8, 2011, pp 832-837.

[5] Zareipour H., Bhattacharya, and Canizares C. A., "Distributed Generation: Current Status and Challenges," IEEE Proceedings Vol. 21, No. 2, 2004, pp 157-164.

[6] Koeppel G., Distributed Generation: Literature Review and outline of the Swiss Solution, Zurich, Internal Report, November 2003.

[7] CIGRE WG 37-23, "Impact of increasing contribution of dispersed generation on power system", final report, September 1998. 
[8] NRECA, The Half-Myths of Distributed Generation, An Issue paper of the National Rural Electric Cooperative Association. 2014, https: //www.cooperative.com/programsservices/bts/Pages/Distribut ed-Generation-Toolkit.aspx Accessed on 03/04/2018 3: 47pm.

[9] Department of Trade and industry (United Kingdom), "Energy White paper: Our Energy Future Creating a Low Carbon Economy", Report, February 2003.

[10] ACRE Energy Policy Group, New Issues Associated with Distributed Generation, Australian CRC for Renewable Energy. 2002, Availablehttp: //www.ceem.unsw.edu.au/sites/default/files/uploads/publicatio ns/CoAG\%20submission.pdf Accessed 03/06/2018

[11] Department of Energy, "Making Connections: Case Studies of Interconnection Barriers and Their Impact on Distributed Power Project,” NREL/SR 200-28053, May 2000.
[12] Allan C., Fangtao D., Andy B., and John C., "Solution for the Connection and Operation of Distributed Generation", Technical Steering Group Report, July 2003, Available http: //webarchive.nationalarchives.gov.uk/20100919182405/http:// www.ensg.gov.uk/assets/solutions.pdf.

[13] Arthur D. L., Distributed Generation: System Interfaces, White Paper, $1999 . \quad$ Available http: //www.encorp.com/ADLittleWhitePaperDGSystemInterfaces. pdf.

[14] Premium Time, Wednesday April $3^{\text {rd }}$, 2019https: //www.premiumtimesng.com/news/top-news/309349-nigeriaspower-generation-increases-in-january-tcn.html Accessed $14 / 02 / 2019$. 